\title{
Sách tác giả Vương Quân Hoàng lưu trữ tại Thư viện Quốc gia Việt Nam
}

Hồ Mạnh Toàn

Ngày 20 tháng 2 năm 2021

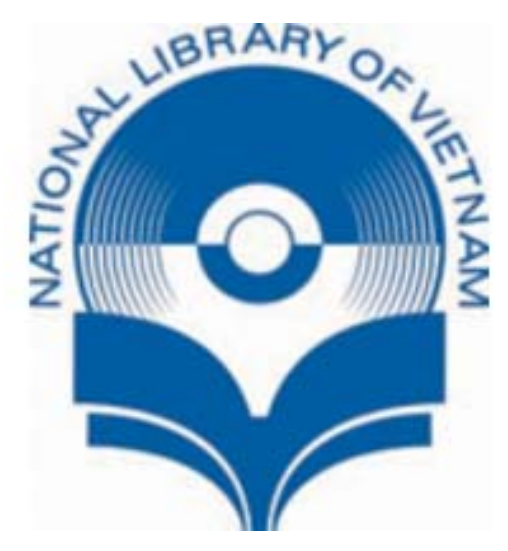

Thư viện Quốc gia Việt Nam

Bibliothèque Nationale du Vietnam

National Library of Vietnam

31 Tràng Thi, Quận Hoàn Kiếm

Hà Nội 100000, Việt Nam

https://nlv.gov.vn

*

$* \quad *$

Văn bản này ghi lại một số thông tin truy xuất nhanh từ hệ thống lưu trữ và giao diện tìm kiếm tài liệu OPAC, một dịch vụ công ích của Thư viện Quốc gia Việt Nam.

Tác giả Vương Quân Hoàng (trường ĐH Phenikaa, Hà Đông, Hà Nội) đang có 4 văn bản dạng sách in lưu trữ tại TVQG Việt Nam.

Đường dẫn truy xuất dữ liệu: 
http://opac.nlv.gov.vn/pages/opac/wpid-search-stype-form-quick-sfield-allkeyword-V\%C6\%B0\%C6\%A1ng\%20Qu\%C3\%A2n\%2OHo\%C3\%AOng.html

Các thông tin xác thực và đường dẫn tới thông tin thư viện của bản ghi lưu trữ cụ thể được cung cấp dưới đây. (ở đây chỉ trích xuất riêng cho sách.)

\section{Bằng chứng cuộc sống: Suy nghĩ vê phát triển bên vững Việt Nam}

1. $\curvearrowleft$ Bằng chứng cuộc sống - Suy nghĩ về phát triển bền vững Việt Nam



Tổng quan $\rightarrow$

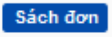

Bạch Ngọc Chiến

H.: Chính trị Quốc gia, 2015

$338.959707 /$ B116C

255tr.: ảnh, $22 \mathrm{~cm}$

Kinh tế; Phát triển bền vững; Việt Nam

Vương Quân Hoàng

http://opac.nlv.gov.vn/pages/opac/wpid-detailbib-id-682072.html

\section{Kinh tế Việt Nam: Thăng trâm và đột phá}

2. $\curvearrowleft$ Kinh tế Việt Nam - Thăng trầm và đột phá

\begin{tabular}{|c|c|c|}
\hline Tổng quan & Vị trí tài liệu Liên kết & \\
\hline & Loại CSDL: & Sách đon \\
\hline & Tác giả: & Phạm Minh Chính \\
\hline & Thông tin $x b$ : & H.: Tri thức, 2009 \\
\hline & Phân loại tài liệu: & $332.09597 / \mathrm{K} 312 \mathrm{~T}$ \\
\hline & Mô tả vât lý: & XXVIII, 554 tr.: bảng, biểu đồ, $22 \mathrm{~cm}$ \\
\hline & Từ khóa: & Kinh tế; Tài chính; Việt Nam \\
\hline & Tác giả bổ sung: & Vương Quân Hoàng \\
\hline
\end{tabular}

Chọn BST Chế độ xem

http://opac.nlv.gov.vn/pages/opac/wpid-detailbib-id-748091.html

Văn minh làm giàu \& nguồn gốc của cải 
3. Văn minh làm giàu \& nguồn gốc của cải

\begin{tabular}{|c|c|c|c|c|c|c|c|}
\hline Tổng quan & Vị trí tài liệu & & & & & & \\
\hline & $\begin{array}{l}\text { Loại CSDL: } \\
\text { Tác giả: } \\
\text { Thông tin xb: } \\
\text { Phân loại tài liệu: } \\
\text { Mô tả vật lý: } \\
\text { Từ khóa: }\end{array}$ & \multicolumn{2}{|l|}{$\begin{array}{l}\text { Sách đơn } \\
\text { Vương Quân Hoàng } \\
\text { H.: Chính trị Quốc gia, } 2007 \\
\text { 306.4/ V115M } \\
\text { XXV, 497tr.: minh hoạ, 24cm } \\
\text { Doanh nghiệp; Văn hoá kinh doanh; Bí quyết thành công }\end{array}$} & \multicolumn{4}{|c|}{ 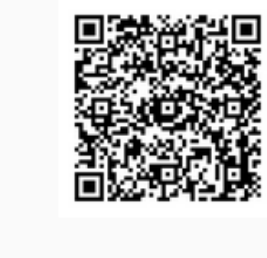 } \\
\hline Tổng quan $\rightarrow$ & & Chọn BST & $\nabla$ & Chế độ xem V & & 0 & 13 \\
\hline
\end{tabular}

http://opac.nlv.gov.vn/pages/opac/wpid-detailbib-id-748111.html

\section{Các phương pháp toán học trong tài chính}

4. $\curvearrowleft$ Các phương pháp toán học trong tài chính

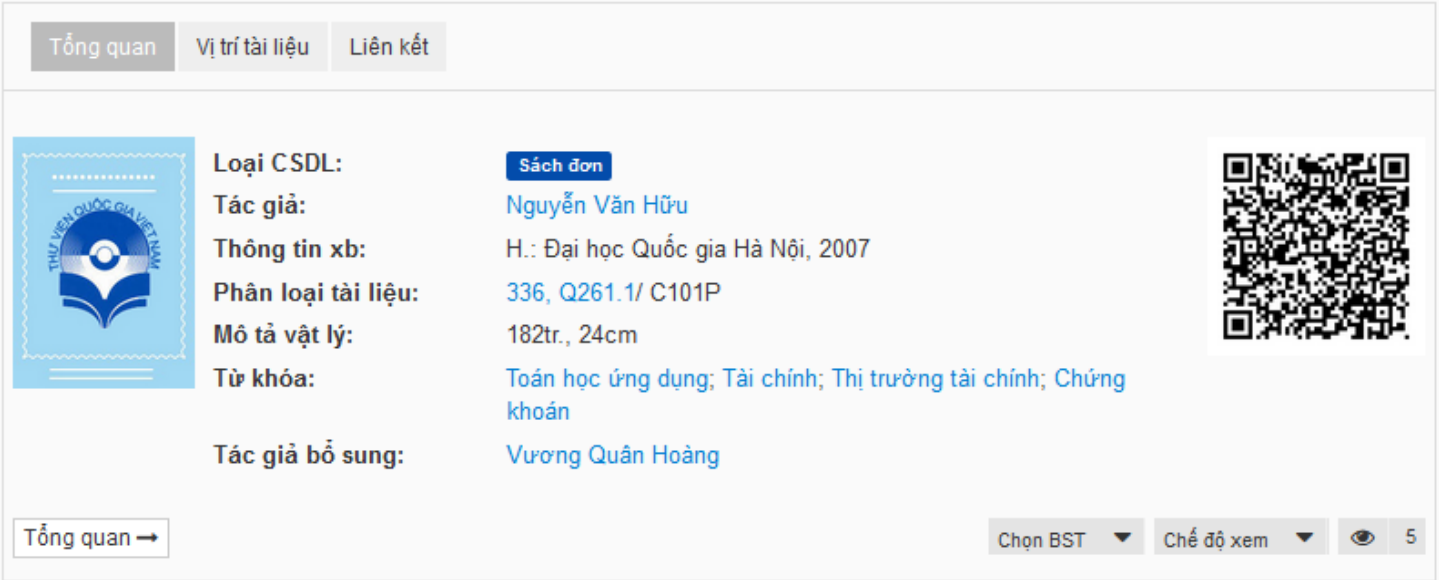

http://opac.nlv.gov.vn/pages/opac/wpid-detailbib-id-328928.html

Các thông tin trình bày ở trên là hình ảnh screenshot được truy xuất ngày 20 tháng 2 năm 2021. Các đường dẫn tới văn bản mở (không cần log-on) và đang hoạt động bình thường.

Bản in pdf trực tiếp từ hệ thống, sử dụng công cụ in của hệ thống OPAC, được trình bày tiếp theo đây. 


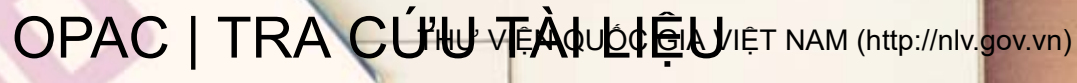

๑ Tổng số ấn phẩm

TVQG

๑ Loại tài liệu

Bài trích

$\checkmark$ Sách đơn

\section{Tác giả}

\section{Năm xuất bản}

\section{Tù̀ khóa}

Thêm kết quả vào góc nghiên cứu

TİM NHANH CO'BẢN NÂNG CAO

\section{Tìm nhanh}

Vương Quân Hoàng

\section{Tìm kiếm}

Tìm thấy $\underline{4}$ Kết quả

Tổng số 845097

Sắp xếp Thích hợp

vHiển thị:

日 国、 
1. Bằng chứng cuộc sống - Suy nghĩ về phát triển bền vững Việt Nam (../opac/wpid-detailbib-id-682072.html)

Tổng quan Vị trí tài liệu Liên kết

Loại CSDL:

Tác giả:

Thông tin xb:

Phân loại tài liệu:

Mô tả vật lý:

Từ khóa:

Tác giả bổ sung:

\section{Sách đơn}

Bạch Ngọc Chiến

H.: Chính trị Quốc gia, 2015

338.959707/B116C

255tr.: ảnh, 22cm

Kinh tế; Phát triển bền vững; Việt Nam

Vương Quân Hoàng

Tổng quan $\rightarrow$

Chọn BST

2

\section{2. $\curvearrowleft$ Kinh tế Việt Nam - Thăng trầm và đột phá (../opac/wpid-detailbib-} id-748091.html)

Tổng quan Vị trí tài liệu Liên kết

\section{Loại CSDL:}

Tác giả:

Thông tin xb:

Phân loại tài liệu:

Mô tả vật lý:

Tùr khóa:

Tác giả bổ sung:

\section{Sách đơn}

Phạm Minh Chính

H.: Tri thức, 2009

332.09597/ K312T

XXVIII, 554tr.: bảng, biểu đồ, 22cm

Kinh tế; Tài chính; Việt Nam

Vương Quân Hoàng

3. Văn minh làm giàu \& nguồn gốc của cải (../opac/wpid-detailbibid-748111.html)

Tổng quan Vị trí tài liệu Liên kết

$\begin{array}{ll}\text { Loại CSDL: } & \text { Sách đơn } \\ \text { Tác giả: } & \text { Vương Quân Hoàng } \\ \text { Thông tin xb: } & \text { H.: Chính trị Quốc gia, } 2007\end{array}$


Phân loại tài liệu:

Mô tả vật lý:

Từ khóa:

Tổng quan $\rightarrow$
306.4/ V115M

XXV, 497tr.: minh hoạ, $24 \mathrm{~cm}$

Doanh nghiệp; Văn hoá kinh doanh; Bí quyết thành công

4. $\curvearrowleft$ Các phương pháp toán học trong tài chính (../opac/wpid-detailbibid-328928.html)

Tổng quan Vị trí tài liệu Liên kết

Loại CSDL:

Tác giả:

Thông tin $x b$ :

Phân loại tài liệu:

Mô tả vật lý:

Tù̀ khóa:

Tác giả bổ sung:

\section{Sách đơn}

Nguyễn Văn Hữu

H.: Đại học Quốc gia Hà Nội, 2007

336, Q261.1/ C101P

$182 \mathrm{tr} ., 24 \mathrm{~cm}$

Toán học ứng dụng; Tài chính; Thị trường tài chính; Chứng khoán

Vương Quân Hoàng

\section{THƯ VIẸN QUÓC GIA VIẸT NAM}

Địa chỉ: Số 31 - Tràng Thi - Hoàn Kiếm - Hà Nội

Điện thoại: 04-38255397 (tổng đài). E-mail: info@nlv.gov.vn 


\section{TÀI LIỆU THAM KHẢO}

[1] Nguyễn Văn Hữu, Vương Quân Hoàng. (2007). Các phương pháp toán học trong tài chính. NXB Đại học Quốc gia, Hà Nội.

[2] Vương Quân Hoàng. (2007). Văn minh làm giàu \& Nguồn gốc của cải. NXB Chính trị Quốc gia, Hà Nội.

[3] Phạm Minh Chính, Vương Quân Hoàng. (2009). Kinh tế Việt Nam: Thăng trầm và đột phá. NXB Chính trị Quốc gia, Hà Nội.

[4] Bạch Ngọc Chiến, Vương Quân Hoàng. (2015). Bằng chứng cuộc sống: Suy nghĩ về phát triển bền vững Việt Nam. NXB Chính trị Quốc gia, Hà Nội. 